\title{
Cortical Cell Orientation Selectivity Fails to Develop in the Absence of ON-Center Retinal Ganglion Cell Activity
}

\author{
Barbara Chapman and Imke Gödecke \\ Center for Neuroscience, University of California, Davis, California 95616
}

Neuronal activity is necessary for the normal development of visual cortical cell receptive fields. When neuronal activity is blocked, cortical cells fail to develop normal ocular dominance and orientation selectivity. Patterned activity has been shown to play an instructive, rather than merely permissive, role in the segregation of geniculocortical afferents into ocular dominance columns. To test whether normal patterns of activity are necessary to instruct the development of cortical orientation selectivity, we studied ferrets raised without $\mathrm{ON}$-center retinal ganglion cell activity. The ON-center blockade was produced by daily intravitreal injections of DL-2-amino-4-phosphonobutyric acid (APB). Effects of this treatment on the development of orientation selectivity in primary visual cortex were assessed using extracellular electrode recordings and optical imaging. In animals raised with an $\mathrm{ON}$-center blockade starting after visual cortical cells are visually driven but still poorly tuned for orientation, cortical cell responsivity was maintained, but no maturation of orientation selectivity was seen. No recovery of orientation tuning was seen in animals treated with APB during the normal period of orientation development and then allowed several months of development without treatment. These results suggest that patterns of neuronal activity carried in the separate ON- and OFF-center visual pathways are necessary for the development of orientation selectivity in visual cortical neurons of the ferret and that there is a critical period for this development.

Key words: visual cortex; activity; DL-2-amino-4phosphonobutyric acid; ON-center pathway; development; ferret
Neuronal activity is vital for the establishment of specific connections and functional architecture in the mammalian visual system. If neuronal activity is blocked during development, the eye-specific segregation of afferents in the lateral geniculate nucleus (LGN) and primary visual cortex fails to occur (LGN: Shatz and Stryker, 1988; Sretavan et al., 1988; Penn et al., 1998) (cortex: Stryker and Harris, 1986), and cortical neurons fail to develop orientation selectivity (Chapman and Stryker, 1993).

The pattern, not merely the presence, of activity is important for the development of cortical ocular dominance. During development, the degree of correlation between the activities of the two retinas appears to instruct the formation of ocular dominance columns. If anticorrelation in the activity between the two eyes is experimentally increased, then sharper than normal columns form, whereas if correlation is increased, no columns form (Stryker and Strickland, 1984).

Patterns of activity also appear to instruct the development of cortical cell orientation selectivity. If the degree of correlation within one eye is artificially increased by electrical stimulation, weaker than normal orientation tuning develops (Weliky and Katz, 1997). However, it is not known what patterns in normal spontaneous or visually driven activity are important for the development and maintenance of orientation selectivity.

Visual experience does not appear to be involved in the initial

\footnotetext{
Received Sept. 16, 1999; revised Dec. 17, 1999; accepted Dec. 20, 1999.

This work was supported by National Institutes of Health Grant EY-11369. Cara Wefers provided expert advice on retinal dissections and histology. Lee Stone provided helpful comments on this manuscript.

Correspondence should be addressed to Barbara Chapman, Center for Neuroscience, 1544 Newton Court, Davis, CA 95616. E-mail: bxchapman@ucdavis.edu.

Dr. Gödecke's present address: Optical Imaging Europe, Am Klopferspitz 19, 82152 München-Martinsried, Germany.

Copyright (C) 2000 Society for Neuroscience $\quad 0270-6474 / 00 / 201922-09 \$ 15.00 / 0$
}

establishment of orientation, which occurs in utero in the monkey (Wiesel and Hubel, 1974) and before eye-opening in the ferret (Chapman and Stryker, 1993; Chapman et al., 1996) and which appears to be primarily independent of vision in the cat (Fregnac and Imbert, 1978; Gödecke et al., 1997; Crair et al., 1998). Vision is necessary, however, for the maintenance of orientation selectivity (Blakemore and Van Sluyters, 1975; Buisseret and Imbert, 1976; Crair et al., 1998).

Retinal "waves" (for review, see Wong, 1999) are unlikely to be the feature of activity responsible for establishing orientation selectivity, because they occur too early in development and their spatial extent is too large compared with the size of cortical cell receptive fields (Erwin and Miller, 1998).

One attractive possibility is that patterns of retinal ganglion cell $\mathrm{ON}$ - and OFF-center activity could instruct the development of orientation selectivity. Computational models have shown that correlations between neighboring ganglion cells with the same center type, and anticorrelations with those of opposite center type, could result in the development of oriented cortical cell receptive fields (Miller, 1992, 1994; Tanaka, 1992).

To study whether normal patterns of activity in the ON and OFF pathways are important for developing cortical orientation selectivity, we have studied ferrets raised with the ON-center pathway silenced by daily intravitreal injections of the mGluR6 glutamate receptor agonist DL-2-amino-4-phosphonobutyric acid (APB) (Slaughter and Miller, 1981). We find that this ON-center blockade appears to "freeze" the development of cortical cell orientation selectivity in an immature state, indicating that the balance between $\mathrm{ON}$ - and OFF-center cell activity is indeed crucial for the development of orientation-selective receptive fields in cortical cells. 


\section{MATERIALS AND METHODS}

Animals. Timed-pregnant ferrets with fitch coat color were obtained from Marshall Farms (New Rose, NY). Ferret kits were raised by their mothers in a University of California (UC), Davis animal care facility under an 18/6 hr light/dark cycle. A total of 37 ferrets were used in these experiments. All eye injections and surgeries were performed according to protocols approved by the UC Davis Animal Care and Use Committee and were in accordance with National Institutes of Health guidelines and the Society for Neuroscience Policy.

Experimental groups. (1) For APB concentration testing, two vitreal concentrations of APB were used: 350 and $700 \mu \mathrm{M}$. Four ferrets aged postnatal day (PND) 28-35 and one adult were used for acute LGN recordings to test the effectiveness of these dosages in blocking the $\mathrm{ON}$-center pathway. Unsuccessful attempts were made to locate and record from the LGN in three younger ferrets aged PND 23-PND 25. (2) For APB eye injections begun before the development of cortical responses, four ferrets were treated with $350 \mu \mathrm{M}$ and four ferrets were treated with $700 \mu \mathrm{M}$ APB starting at PND 21 and continuing for 24-33 d. Optical imaging of and cortical microelectrode recordings from visual cortex were performed in all of these animals, and LGN recordings were performed in two animals treated with each APB concentration. (3) For saline controls, four ferrets were treated with $0.9 \% \mathrm{NaCl}$ starting at PND 21 and continuing for 24-33 d. Optical imaging of visual cortex was performed in all of these animals. (4) For APB eye injections begun after the development of cortical visual responses but before the maturation of cortical orientation selectivity, four ferrets were treated with $350 \mu \mathrm{M}$ APB starting at PND 28 and continuing for 21-33 d. Four ferrets were treated with $700 \mu \mathrm{M}$ APB starting at PND 28 and continuing for 21-33 d. Optical imaging of visual cortex was performed in all animals, and cortical electrode recordings were performed in the $700 \mu \mathrm{M}$ APB animals. (5) For APB eye injections started after cortical orientation selectivity is essentially adult-like, four ferrets were treated with $700 \mu \mathrm{M}$ APB starting at PND 42 and continuing for 28-33 d. Optical imaging of visual cortex was performed in all of these animals. (6) For recovery from the effects of APB, four ferrets were treated with $700 \mu \mathrm{M}$ APB starting at PND 28 and continuing for $22 \mathrm{~d}$, before a period of recovery lasting 46-50 d. Optical imaging of and cortical electrode recordings from visual cortex were performed in all of these animals. (7) For retinal histology, retinas from two animals in each of groups 2-4 and two normal PND 52 animals (used in other experiments) were prepared for Nissl staining.

Eye injections. Daily $(24 \pm 2 \mathrm{hr})$ binocular intravitreal eye injections of APB (Calbiochem, La Jolla, CA) in $0.9 \%$ saline or of $0.9 \%$ saline alone were performed. Isofluorane anesthesia was used. Electrocardiograms (EKGs) and breathing were monitored during injections. For the first injection, a small hole was made just posterior to the scleral margin using the very tip of a 30 ga needle. Injections were done using a 33 ga needle on a Hamilton syringe. All subsequent injections were made into the same hole. APB injection volumes needed to create a fixed dosage were calculated using mean measured eye diameters from postmortem agematched ferrets used in other experiments (Fig. $1 A$ ), by assuming that the eye is a sphere and that the posterior chamber occupies two-thirds of its volume. Injection volumes ranged from 2.3-6 $\mu$ l to produce a constant vitreal concentration as the eye grows. After the injections, ferrets received antibiotic ophthalmic ointment (Chloroptic) and prophylactic broad-spectrum antibiotics (Flocillin) intramuscularly. The animals were returned to their mothers and littermates as soon as they recovered from anesthesia (3-5 min). The animals' health and weight were monitored daily. No health problems were seen, and the injected animals' behavior was indistinguishable from normal. Experimental animals gained weight at the same rate as normal controls (Fig. $1 B$ ).

Surgeries. For optical imaging and electrophysiological recordings, animals were prepared as follows. Anesthesia was induced using a mixture of acepromazine $(0.04 \mathrm{mg} / \mathrm{kg})$ and ketamine $(40 \mathrm{mg} / \mathrm{kg})$ intramuscularly, and $0.4 \mathrm{mg}$ atropine sulfate intramuscularly was given to reduce mucus accumulation. A tracheotomy was performed, and anesthesia was maintained using 1-2\% isofluorane in 2:1 oxygen/nitrous oxide. Ventilation was adjusted to produce an end-tidal carbon dioxide reading of $3.5-4 \%$. EKG was monitored throughout the experiment, and body temperature was maintained at $37.5^{\circ} \mathrm{C}$. The animals were placed in a modified kitten stereotax. Atropine sulfate and neosynephrine eye drops were administered, and contact lenses were inserted. The scalp was incised, a small craniotomy was performed over the caudal pole of the left hemisphere, and the dura was retracted. If any signs of brain edema were observed, a cisternal puncture was performed before retracting the dura. Agar $(2 \%)$ in $0.9 \%$ saline was used to cover the brain. In optical imaging experi-
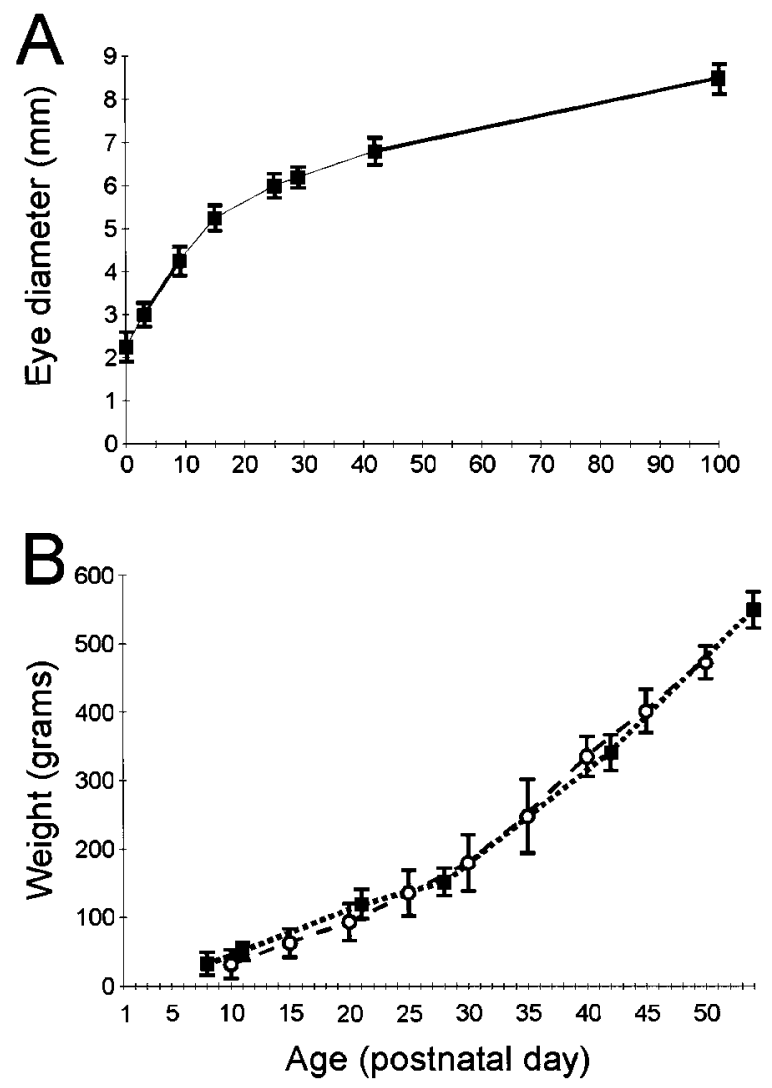

Figure 1. Eye diameter and body weight of developing ferrets. A, Eye diameter measured from postmortem normal ferrets. These eye diameters were used to calculate the amount of APB to be injected to produce the desired vitreal concentration (see Materials and Methods). B, Ferret growth rates were unaffected by APB injections. Round symbols show weights of ferrets undergoing APB injections $(n=42)$. Square symbols show the mean weights of normal age-matched controls $(n=5)$. Error bars indicate the SD.

ments, a glass coverslip was applied on the agar while it was still liquid. Lidocaine was applied to all wound margins.

Optical imaging. Optical imaging of intrinsic signals was performed using the ORA 2001 imaging set-up (Optical Imaging Inc., Germantown, NY). Imaging experiments were performed 24 or $48 \mathrm{hr}$ after the last eye injection or at longer delays for recovery experiments. No differences were seen in the results of 24 versus $48 \mathrm{hr}$ conditions; however, all of the data shown in the figures here are from experiments performed $48 \mathrm{hr}$ after the last injection to be absolutely sure that there were no residual APB effects at the time of imaging. Visual stimuli consisted of full-screen moving square wave gratings at four different orientations. The drift rate was $10^{\circ} / \mathrm{sec}$, and the spatial frequency was $0.5 \mathrm{cycles} /{ }^{\circ}$. Orientation activity maps were calculated against cocktail blanks consisting of the sum of images obtained in response to all four stimulus orientations, and first frame analysis was used in some cases to minimize blood vessel artifacts (Grinvald et al., 1986; Bonhoeffer and Grinvald, 1996).

Electrophysiological recordings. Multiunit extracellular LGN recordings and single-unit extracellular cortical recordings were performed using tungsten microelectrodes (Micro Probe, Gaithersburg, MD). Cortical penetrations were angled in the coronal plane to cross several orientation columns in each penetration. LGN penetrations were vertical. Spike times were collected using Hist hardware and software (Spike Systems Inc., New York, NY), and poststimulus time histograms (PSTHs) and tuning curves were calculated using Microsoft (Seattle, WA) Excel software. Visual stimuli were generated using VisionWorks (Vision Research Graphics, Durham, NH). Flashing light-dark circles were used to stimulate LGN cells, and moving light bars were used for cortical recordings. Orientation selectivity indices (OSI) were calculated from cortical tuning curves using a Fast Fourier Transform and normalizing the amplitude of the second harmonic as follows: OSI $=(A 2 / A 2+D C) * 100$ (Chapman and Stryker, 1993). 

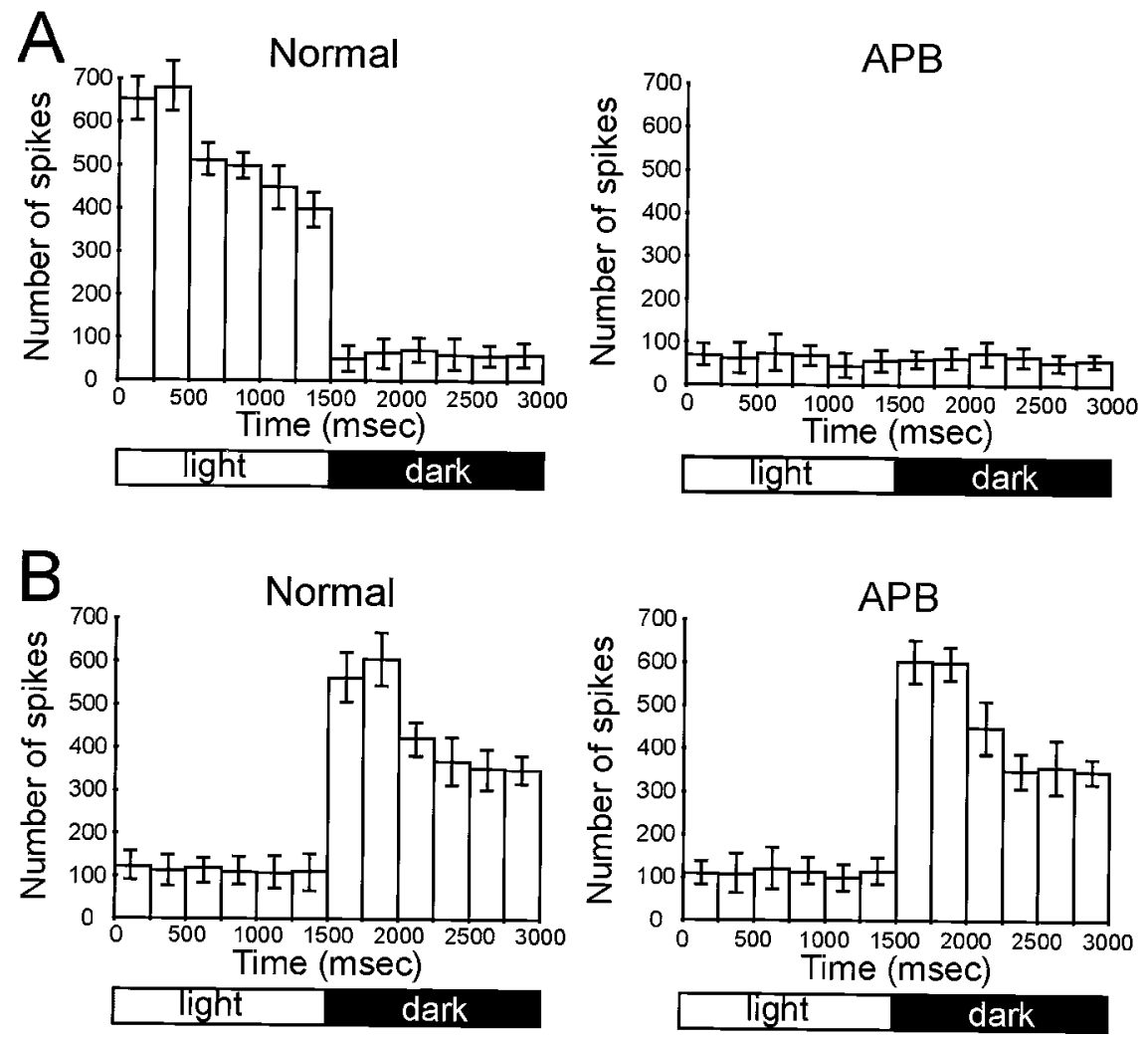

Figure 2. Intravitreal APB injections silence ONcenter activity in ferret LGN but leave OFF-center activity intact. $A$, PSTHs showing ON-center responses recorded in PND 28 ferret LGN lamina A. Left, Response before eye injection. Right, Response at the same location after the injection of APB sufficient to produce a vitreal concentration of 700 $\mu \mathrm{M}$ APB into the contralateral eye. $B$, PSTHs showing OFF-center responses recorded in PND 28 ferret LGN lamina A1. Left, Response before eye injection. Right, Response at the same location after the injection of APB sufficient to produce a vitreal concentration of $700 \mu \mathrm{M}$ APB into the ipsilateral eye. $C$, PSTHs showing responses in ON (left) and OFF (right) leaflets in lamina A of the LGN from an animal treated with binocular $700 \mu \mathrm{M}$ APB at PND $28-50$.

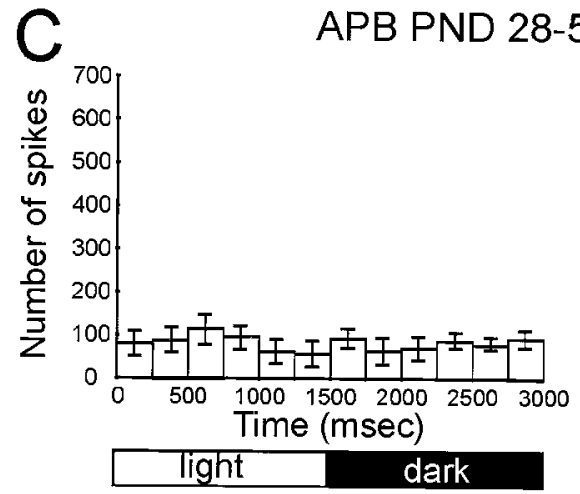

APB PND 28-50, recording PND 50



Retinal histology. APB-injected and normal age-matched control animals were killed by overdose of sodium pentobarbital after optical imaging and/or physiology experiments and perfused with $4 \%$ paraformaldehyde. Retinas were dissected out of the eyes, $1 \mathrm{~mm}$ "punches" were embedded in 5\% agar, and $30 \mu \mathrm{m}$ cross-sections were cut on a vibratome. Sections were mounted on slides, stained for Nissl substance with thionin, coverslipped, and photographed.

\section{RESULTS}

\section{Does APB provide an effective and selective blockade of $\mathrm{ON}$-center retinal ganglion cell activity?}

In initial experiments, the acute effects of APB on ON- and OFF-center LGN cells were studied. Four ferrets aged PND 28-35 and one adult ferret were used. An electrode penetration was made in a region in which the track passed through $\mathrm{ON}-$ and OFF-center leaflets in both the contralateral (lamina A) and ipsilateral (lamina A1) eye layers of the LGN. After recording normal responses in the LGN to flashing light-dark circles, the electrode was placed in the lamina A OFF leaflet in three animals or the lamina A ON leaflet in the other two animals. Normal PSTHs of the multiunit responses at that location were recorded. APB calculated to produce a vitreal concentration of either 350 (in two animals) or 700 (in the other three animals) $\mu \mathrm{M} \mathrm{APB} \mathrm{was}$ injected into the vitreous humor of the contralateral eye. After 30 min, another PSTH was recorded at the same electrode location. The electrode was then moved down to a location in lamina A1 in which responses were of the opposite center type than at the recording location in lamina A. Normal PSTHs were collected, APB was injected into the ipsilateral eye, and $30 \mathrm{~min}$ later, PSTHs were again recorded. In all cases, either 350 or $700 \mu \mathrm{M}$ APB was found to completely abolish $\mathrm{ON}$-center responses but had no significant effect on OFF-center responses (Fig. $2 A, B$ ). In each experiment, LGN recordings were continued every hour until ON-center activity began to recover. In animals with $350 \mu \mathrm{M}$ APB, ON-center activity was fully blocked for 8-14 hr; in animals with $700 \mu \mathrm{M}$ APB, ON-center activity was blocked for 22-28 hr. These results are similar to those seen previously in monkey 
A

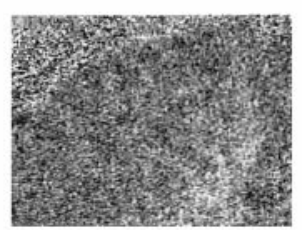

$0^{\circ}$
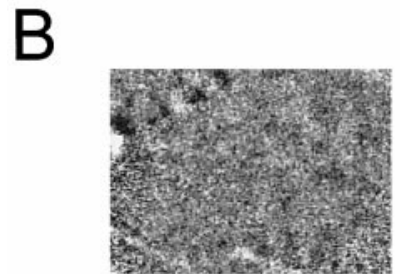

$0^{\circ}$

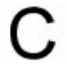

Binocular 350 $\mu$ M APB PND 21-48

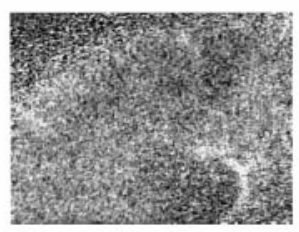

$45^{\circ}$ Binocular $700 \mu \mathrm{M}$ APB PND 21-52

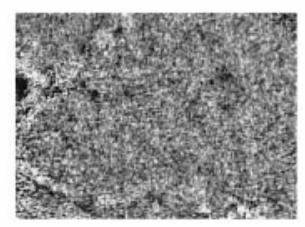

$45^{\circ}$

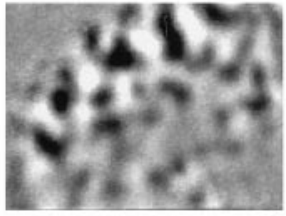

$45^{\circ}$

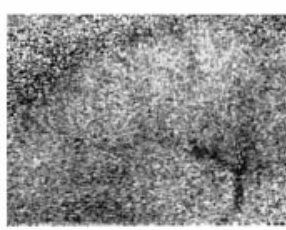

$90^{\circ}$

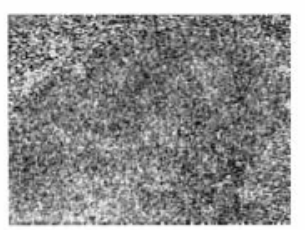

$135^{\circ}$

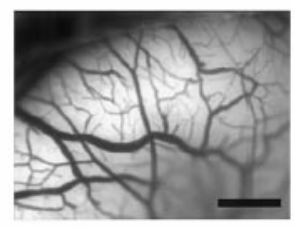

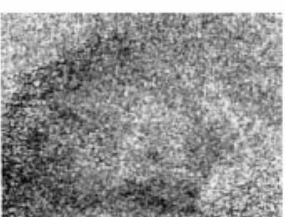

$90^{\circ}$

Normal PND 51

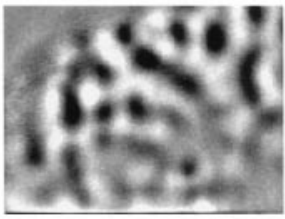

$90^{\circ}$
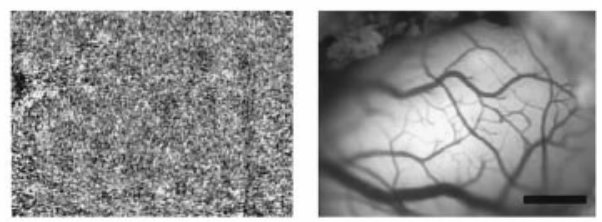

$135^{\circ}$
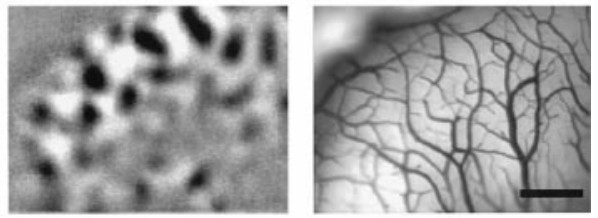

$135^{\circ}$



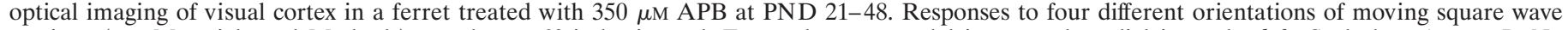

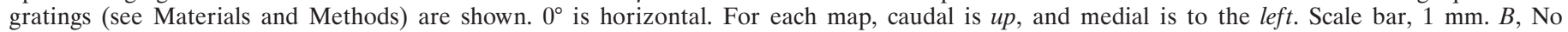

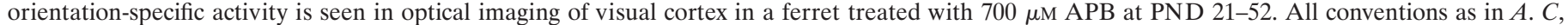
Normal PND 51 orientation activity maps are shown for comparison. All conventions as in $A$.

(Knapp and Schiller, 1984), rabbit (Knapp and Schiller, 1984), and cat (Horton and Sherk, 1984). The effective and selective blockade of ON-center activity could be maintained during prolonged APB treatment; after daily intravitreal APB injections from PND 28 to PND 50, no visually driven activity was recorded in ON LGN leaflets, whereas normal activity was recorded in OFF leaflets (Fig. 2C).

We were unsuccessful in performing the same sort of effectiveness and selectivity studies in younger animals. Attempts were made to record from the LGN in three ferrets aged PND 23-25. Unfortunately, we were not able to locate the LGN in these very young animals. Therefore, we do not know the selectivity of APB at the earliest ages it was used in some of our experiments. APB has been shown to be nonselective in the very young ferret retina (PND 5-7) in which calcium imaging demonstrates that even a very small concentration of APB $(1 \mu \mathrm{M}$ applied to isolated retinas) blocks all retinal ganglion cell spontaneous activity (R. O. L. Wong, personal communication). By PND 21, the earliest injection time point used in our study, low concentrations of APB begin to have a more specific effect, but concentrations that fully block ON-center ganglion cells still decrease activity in OFFcenter cells (Wong et al., 2000). Because many times higher vitreal concentrations than perfusing concentrations of APB are needed to produce the same effect (Knapp and Schiller, 1984), we cannot directly compare the concentrations used in our study with those applied to isolated retina. However, the results of Wong et al. suggest that, in the youngest animals used in our study, APB injections may have blocked at least some and possibly all of the
OFF-center retinal ganglion cell activity, in addition to blocking the ON-center activity.

\section{What are the effects of intravitreal APB injections begun before the ferret cortex is visually responsive and continued through the normal period of cortical orientation selectivity maturation?}

Ferrets received daily intravitreal injections of APB designed to yield a vitreal concentration of 350 or $700 \mu \mathrm{M}$ starting on PND 21, when some spontaneous but no visually driven activity can be recorded in the cortex (Chapman and Stryker, 1993) and continuing through PND 45-54 when cortical orientation tuning is adultlike (Chapman and Stryker, 1993; Chapman et al., 1996). Twentyfour to $48 \mathrm{hr}$ after the last eye injection, optical imaging showed no orientation-specific activity in the primary visual cortex in all eight treated animals (Fig. 3). Microelectrode recordings in visual cortex were performed to look for visually driven activity. Five to 10 radial microelectrode penetrations through the entire depth of visual cortex were made in each hemisphere in each of the eight animals. Recordings were obtained at $20 \mu \mathrm{m}$ intervals. No visually driven activity was seen. This result appears to be attributable to effects of the APB treatment on the development of the cortex itself and is not attributable to damage to the retina or changes in the LGN. Retinal histology from treated animals showed normal morphology (Fig. 4A), and LGN recordings from two ferrets in each APB concentration group showed normal ON and OFF responses at the time of the experiments (Fig. 4B). Four control animals were given daily intravitreal $0.9 \%$ saline injec- 

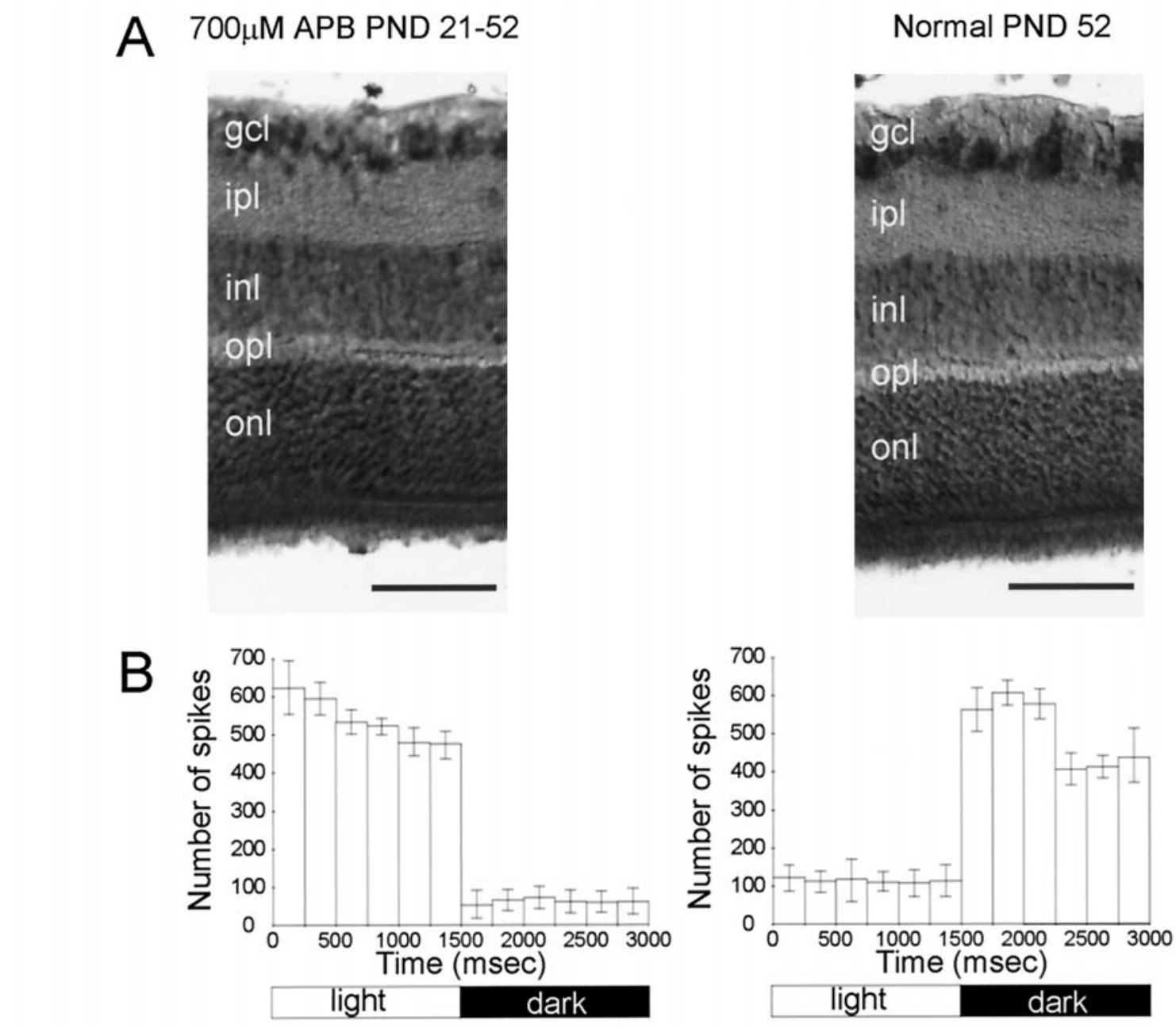

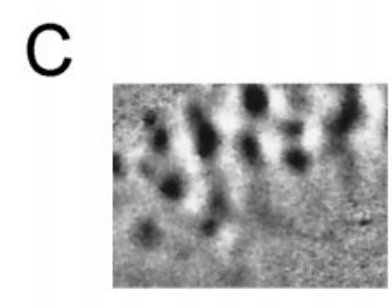

$0^{\circ}$

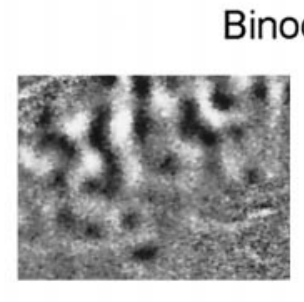

$45^{\circ}$

Binocular $\mathrm{NaCl}$ PND 21-50

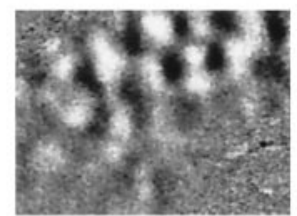

$90^{\circ}$



$135^{\circ}$

Figure 4. Controls to rule out retinal damage from injections. $A$, Nissl-stained sections through retina from a ferret receiving daily intravitreal injections of $700 \mu \mathrm{M}$ APB at PND 21-52 (left) and normal age-matched control (right) appear identical. gcl, Ganglion cell layer; ipl, inner plexiform layer; inl, inner nuclear layer; opl, outer plexiform layer; onl, outer nuclear layer. Scale bar, $50 \mu \mathrm{m}$. B. PSTHs of LGN activity recorded on PND 52 in lamina A of a ferret treated with $700 \mu \mathrm{M}$ APB at PND 21-50. Both ON- and OFF-center activity appear normal. $C$, Normal layout and intensity of orientation maps (Chapman et al., 1996; Chapman and Bonhoeffer, 1998) is seen in visual cortex of a ferret treated with $0.9 \%$ daily intravitreal injections matched in volume to APB injections. All conventions as in Figure $3 \mathrm{~A}$.

tions starting at PND 21. Optical imaging in these animals showed normal development of orientation maps (Fig. 4C), indicating that the lack of cortical responsiveness in the APB-treated animals was attributable to the effects of the drug and not to any nonspecific effects of eye injections.

The first week of APB treatment in these animals may have provided a nonspecific activity blockade in the retina, effecting OFF-center activity to an unknown extent as well as silencing ON-center activity (see above). Therefore, we do not know whether the failure of development of cortical responsiveness would be caused by a selective ON-center blockade or whether a total activity blockade is necessary to produce this effect.

\section{What are the effects of ON-center retinal ganglion cell blockade begun after cortex is visually responsive but before the maturation of cortical orientation selectivity?}

Ferrets received daily intravitreal injections of APB designed to yield a vitreal concentration of 350 or $700 \mu \mathrm{M}$ starting on PND 28, when single cell orientation tuning is weak (Chapman and 
A

Binocular 700 $\mu$ M APB PND 28-52

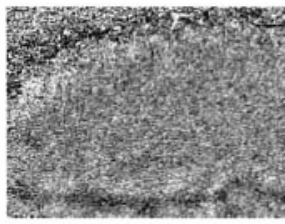

$0^{\circ}$

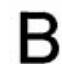

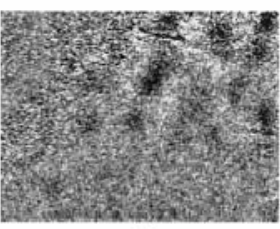

$0^{\circ}$

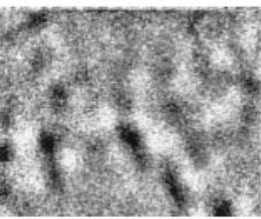

$0^{\circ}$

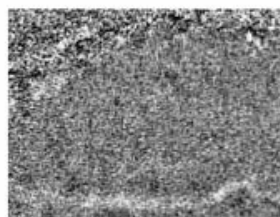

$45^{\circ}$

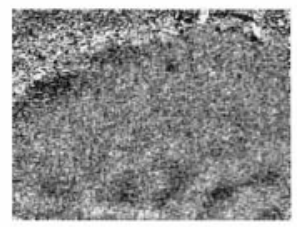

$90^{\circ}$

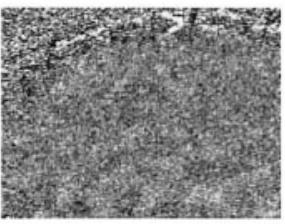

$135^{\circ}$

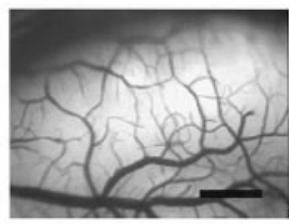

Binocular 350 $\mu \mathrm{M}$ APB PND 28-52

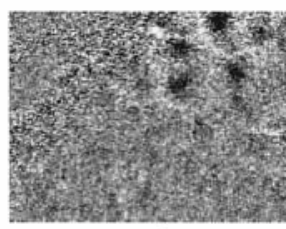

$45^{\circ}$

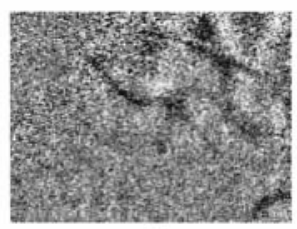

$90^{\circ}$

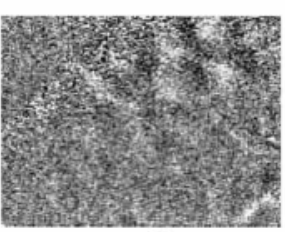

$135^{\circ}$

Binocular 350 $\mu$ M APB PND 28-49

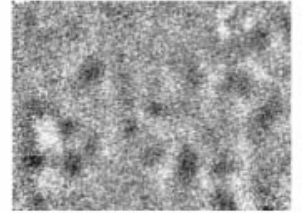

$45^{\circ}$

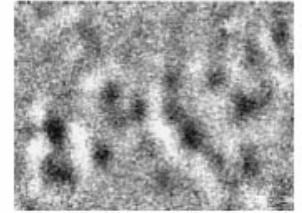

$90^{\circ}$

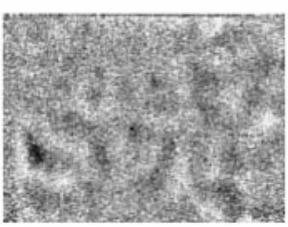

$135^{\circ}$
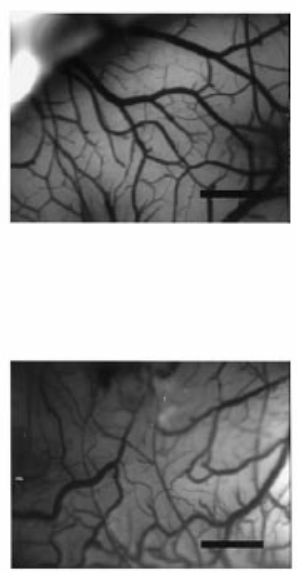

Figure 5. Total ON-center blockade started at PND 28 prevents orientation selectivity development; part-time blockade reduces or delays development. $A$, No orientation-specific activity is seen in optical imaging of visual cortex in a ferret treated with $700 \mu \mathrm{M}$ APB at PND $28-52$. $B$, Faint orientation activity maps with normal layouts are seen in ferrets treated with $350 \mu \mathrm{M}$ APB at PND 28-50. All conventions as in Figure $3 A$.

Stryker, 1993) and no orientation-specific activity is seen by optical imaging (Chapman et al., 1996), and continuing through PND 45-54 when cortical orientation tuning is adult-like (Chapman and Stryker, 1993; Chapman et al., 1996). Twenty-four to 48 $\mathrm{hr}$ after the last eye injection, optical imaging showed no orientation-specific activity in the primary visual cortex of all four animals treated with $700 \mu \mathrm{M}$ APB (Fig. 5A). Ferrets treated with $350 \mu \mathrm{M}$ APB showed faint orientation maps, with some variability between animals in the strength of the maps (Fig. $5 B$ ). In all cases, these maps were weaker than those seen in normal age-matched animals (Chapman et al., 1996; Chapman and Bonhoeffer, 1998) or in saline-treated control animals (Fig. 4C).

Electophysiological recordings were made in the primary visual cortex of all four animals treated with $700 \mu \mathrm{M}$ APB. Orientation tuning histograms were compiled for a total of 93 cortical cells, and OSIs were calculated. The distribution of orientation tunings seen in the cortex was statistically indistinguishable from that seen in normal ferrets at the age that APB injections began (Fig. 6 ). This suggests that specific blockade of ON-center retinal ganglion cells (Fig. 2) prevents the maturation of orientation selectivity in ferret visual cortex, freezing the cortex in an immature state. The lack of orientation tuning development seen in the cortex of $700 \mu \mathrm{M}$ APB-treated animals is similar to that seen in ferrets treated with intracortical infusions of the sodium channel blocker tetrodotoxin (Chapman and Stryker, 1993; Fig. 6), indicating that OFF-center activity alone is not sufficient to allow any maturation of orientation selectivity. The effects of the APB treatment on cortical cell responsiveness are also similar to those seen with TTX treatment. Both treatments prevent maturation of responsiveness, producing a distribution of cortical cell responsiveness indistinguishable from that seen at the beginning of the treatment period [mean firing rate above spontaneous level in response to preferred orientation (spikes/sec): normal at $\sim$ PND $28(n=93$ cells $), 16.38 \pm 1.16$; normal at $\sim$ PND $50(n=79$ cells $)$, $25.64 \pm 2.05 ;$ TTX $(n=56$ cells $), 16.52 \pm 1.53 ; 700 \mu \mathrm{M} \mathrm{APB}(n=$ 78 cells), $16.46 \pm 1.42$ ] (normal and TTX data from Chapman and Stryker, 1993).

The formation of relatively weak maps with normal orientation layouts in the cortex of animals treated with $350 \mu \mathrm{M}$ APB suggests that the presence of normal activity patterns for approximately half of each day during development (see above) is sufficient for orientation tuning to develop, although this tuning appears to be weakened or delayed in its maturation by the half-time ON-center activity blockade. This result is in line with previous experiments in which activity was artificially correlated across the retina by electrical stimulation of the optic nerve for $10 \%$ of the time during development, and weak orientation maps with normal layout were seen (Weliky and Katz, 1997).

\section{Does ON-center activity blockade affect cortical responses if APB injections are started after cortical cell orientation tuning is mature?}

In four ferrets, $700 \mu \mathrm{M}$ APB injections were begun on PND 42 and continued for 4-5 weeks. At PND 42, cortical cell orientation tuning is adult-like (Chapman and Stryker, 1993; Chapman et al., 1996), but visual cortex is still very plastic; geniculocortical affer- 




Figure 6. ON-center blockade prevents development of orientation selectivity in single cells. Orientation selectivity distributions for single cells recorded in animals treated with $700 \mu \mathrm{M}$ APB starting at PND 28 are compared with those from normal postnatal week 4 (PNW4) ferrets, normal $P N W 7$-adult ferrets, and ferrets treated with intra-cortical TTX infusion starting at PND 28 (data from all animals other than APBtreated are from Chapman and Stryker, 1993). Cumulative percentages of cells at each OSI are shown. The distribution for APB-treated animals is statistically indistinguishable from those for normal postnatal week 4 or TTX-treated animals (Mann-Whitney $U$ test; $p>0.25$ ).

ents are still segregating into ocular dominance columns (Ruthazer et al., 1999), and the cortex is still maximally sensitive to the effects of monocular deprivation (Issa et al., 1999). However, APB treatment at this stage of development had no effect on cortical orientation tuning (Fig. 7A), suggesting that ON-center activity is needed for the maturation of orientation selectivity but not for its maintenance after selectivity is fully established.

\section{Is there a critical period for the development of cortical cell orientation tuning?}

Recovery experiments were performed in four ferrets to determine whether normal patterns of activity late in development after a period of $\mathrm{ON}$-center activity blockade could allow delayed maturation of cortical cell orientation selectivity. Animals were treated with $700 \mu \mathrm{M}$ APB from PND 28 to PND 50 and then allowed to recover for $48-50 \mathrm{~d}$. No sign of delayed orientation selectivity development was seen in these animals; optical imaging showed no orientation-specific activity (Fig. 7B), and cortical recordings showed orientation tuning histograms similar to those seen in animals undergoing the same APB treatment without the recovery period (data not shown). The results in Figure 7 show that there is a critical period for orientation development in the ferret visual cortex.

\section{DISCUSSION}

Neuronal activity is thought to play an instructive role in the development of visual cortical cell receptive field structure. Our results, showing that orientation selectivity fails to mature in the absence of ON-center activity, suggest that the correlation structure of ON- and OFF-center inputs to visual cortex may instruct the development of orientation tuning.

Correlations in patterns of activity are known to be important for the development of ocular dominance in primary visual cortex. In normal animals, some interocular correlation is present in spontaneous LGN activity (Weliky and Katz, 1999) and is presumably increased by visually driven activity. This normal degree of interocular correlation results in the development of relatively sharp ocular dominance columns in primary visual cortex (Hubel et al., 1977; Shatz and Stryker, 1978; LeVay et al., 1980). If the degree of correlation between the two eyes is decreased by misalignment of the eyes (Hubel and Wiesel, 1965; Shatz et al., 1977; Löwel et al., 1998) or if activity is anticorrelated in the two eyes by alternating electrical stimulation of the optic nerves (Stryker and Strickland, 1984), then greater than normal eye-

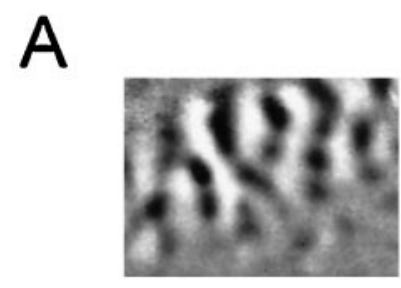

$0^{\circ}$
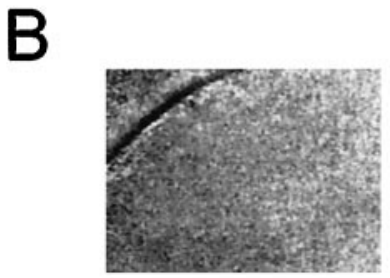

$0^{\circ}$

Binocular 700 $\mu \mathrm{M}$ APB PND 42-75

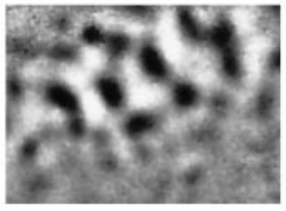

$45^{\circ}$

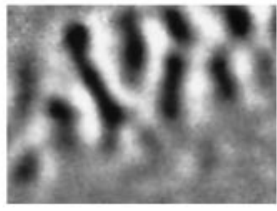

$90^{\circ}$



$135^{\circ}$

Binocular 700 $\mu$ M APB PND 28-50, Imaging PND 100

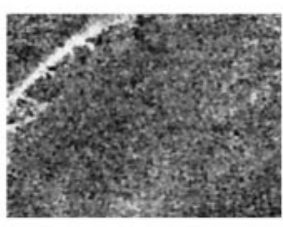

$45^{\circ}$



$90^{\circ}$

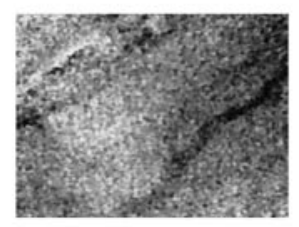

$135^{\circ}$
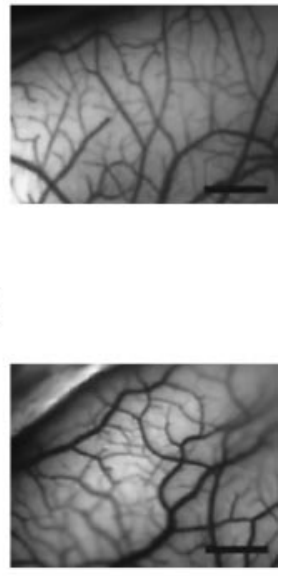

Figure 7. Critical period for orientation selectivity development. A, Orientation selectivity is unaffected by ON-center activity blockade begun after orientation selectivity is mature. Normal layout and intensity of orientation maps (Chapman et al., 1996; Chapman and Bonhoeffer, 1998) is seen in visual cortex of a ferret treated with $700 \mu \mathrm{M}$ APB at PND 42-75. B. There is no recovery from the effects of blocking ON-center activity during the period of orientation maturation. No orientation-specific activity is seen in optical imaging performed on PND 100 in visual cortex of a ferret treated with 700 $\mu \mathrm{M}$ APB at PND 28-50. All conventions as in Figure $3 A$. 
specific segregation of geniculocortical afferents is seen. On the other hand, if interocular correlations are increased by simultaneous stimulation of the axons from the two eyes, no segregation occurs and ocular dominance columns fail to form (Stryker and Strickland, 1984).

The spatial correlation structure of activity within one retina may be important for the development of cortical cell orientation selectivity. Computational models have shown that cortical cell orientation selectivity can result from Hebbian learning rules if the inputs to cortex are correlated between cells of like center type and anticorrelated between cells of opposite center type at small retinotopic distances, and anticorrelated between cells of like center type and correlated between cells of opposite center type at slightly larger retinotopic distances (Miller, 1992, 1994; Tanaka, 1992). If normal patterns of activity are disrupted by increasing the correlations in activity for all cells across the retina by electrically stimulating the optic nerve, weaker than normal orientation selectivity develops (Weliky and Katz, 1997), implicating patterned activity in the development of orientation but leaving open the question of what sort of patterning is important. Interestingly, $8 \mathrm{~Hz}$ stroboscopic rearing, which presumably also increases spatial correlations across the retina within both the $\mathrm{ON}$ and the OFF pathway but which preserves or enhances anticorrelations between $\mathrm{ON}$ - and OFF-center activity, does not affect the development of orientation selectivity (Cynader and Chernenko, 1976; Pasternak et al., 1985; Humphrey and Saul, 1998).

Our finding that pharmacological blockade of ON-center activity during development prevents the maturation of orientation tuning provides the first direct evidence for the idea that correlations and anticorrelations in $\mathrm{ON}$ - and OFF-center activity play an important role in the development of orientation selectivity. One caveat in interpreting our results, however, is the possibility that there could be some threshold of overall activity necessary to provide a permissive environment for orientation selectivity development. By blocking ON-center activity, we have presumably approximately halved the overall levels of input activity to visual cortex. However, we do not think it is likely that our results are attributable to merely lowering overall levels of activity, because enucleation (which also presumably approximately halves input activity to the cortex) has no effect on the development of orientation selectivity (Fregnac et al., 1981; Weliky and Katz, 1997).

It will be interesting to determine in future experiments more details of the receptive field structure of cortical cells in ferrets raised without ON-center activity. Simple cell orientation tuning is thought to depend at least in part on the existence of parallel elongated ON and OFF subfields (Hubel and Wiesel, 1962). In the cat, individual simple cells often receive both ON- and OFFcenter LGN inputs (Tanaka, 1983; Ferster, 1988; Reid and Alonso, 1995; Hirsch et al., 1998). The lack of orientation selectivity we see in our animals raised without ON-center activity may well be caused by rearrangements of the ON- and OFFcenter geniculate inputs to cortical simple cells. ON-center inputs to the cortex might be mostly or completely missing in the APB-treated animals, having lost out in an activity-dependent competition similar to the loss of closed eye inputs to cortex seen in monocularly deprived animals (LeVay et al., 1980). Alternatively, normal numbers of ON inputs might be present but without the normal spatial segregation of ON and OFF inputs, analogous to the lack of retinal ganglion cell dendritic stratification seen in kittens treated with APB at a very young age (Bodnarenko and Chalupa, 1993; Bodnarenko et al., 1995). It is not clear to what extent convergent $\mathrm{ON}$ and OFF input to simple cells occurs in the normal adult ferret. Given the high degree of anatomical segregation of ON and OFF LGN inputs to the ferret visual cortex (Zahs and Stryker, 1988; Chapman et al., 1991), it is possible that the ferret has a much higher percentage of exclusively $\mathrm{ON}$ and exclusively OFF simple cells than does the cat. Therefore, careful studies of simple cell receptive fields in normal ferrets must be completed before attempting to study the rearrangements of inputs to simple cells that may result from the ON-center retinal ganglion cell activity blockade.

Our results show that there is a critical period during which normal patterns of activity must be present for cortical orientation selectivity to develop. Animals raised with only OFF-center retinal ganglion cell activity during the normal period of orientation development cannot later develop orientation when allowed long periods of recovery with normal retinal activity. Such a critical period is well established in the developmental plasticity of ocular dominance columns in response to monocular deprivation (Wiesel and Hubel, 1963; Hubel and Wiesel, 1970; Issa et al., 1999), although it has not been directly determined whether there is a critical period for the normal development of ocular dominance. Although our experiments do not delineate the time course of the orientation selectivity critical period, we do know that the orientation critical period predates the end of the ocular dominance critical period, because our ON-center activity blockade ended near the beginning of the ferret ocular dominance critical period (Issa et al., 1999). This is not surprising because the normal development of orientation selectivity (Albus and Wolf, 1984; Chapman and Stryker, 1993) predates the development of ocular dominance columns (LeVay et al., 1980; Ruthazer et al., 1999).

There is increasing circumstantial evidence that the development of orientation selectivity in primary visual cortex occurs through the same mechanisms as the development of ocular dominance. Both processes have a critical period (Wiesel and Hubel, 1963; Hubel and Wiesel, 1970; Issa et al., 1999; present results). Both are activity-dependent (Stryker and Harris, 1986; Chapman and Stryker, 1993). Neither process requires visually driven activity for its initial establishment (Wiesel and Hubel, 1974; Chapman and Stryker, 1993; Chapman et al., 1996; Gödecke et al., 1997; Crair et al., 1998), but vision is critical for the maintenance of both orientation selectivity (Blakemore and Van Sluyters, 1975; Buisseret and Imbert, 1976; Crair et al., 1998) and ocular dominance (Blakemore and Van Sluyters, 1975; Fregnac and Imbert, 1978). Finally, patterns of activity appear to instruct the development of both ocular dominance (Stryker and Strickland, 1984) and orientation selectivity (Weliky and Katz, 1997; present results). Future work, including the study of receptive field structure in animals raised with an ON-center blockade, will determine whether the development of orientation, like that of ocular dominance (Wiesel and Hubel, 1963; Hubel et al., 1977; Shatz and Stryker, 1978; LeVay et al., 1980; Stryker and Strickland, 1984; Antonini and Stryker, 1993), requires competition between geniculocortical afferents with different patterns of activity.

\section{REFERENCES}

Albus K, Wolf W (1984) Early post-natal development of neuronal function in the kitten's visual cortex: a laminar analysis. J Physiol (Lond) 348:153-185.

Antonini A, Stryker MP (1993) Rapid remodeling of axonal arbors in the visual cortex. Science 260:1819-1821.

Blakemore C, Van Sluyters RC (1975) Innate and environmental factors 
in the development of the kitten's visual cortex. J Physiol (Lond) 248:663-716.

Bodnarenko SR, Chalupa LM (1993) Stratification of ON and OFF ganglion cell dendrites depends on glutamate-mediated afferent activity in the developing retina. Nature 364:144-146.

Bodnarenko SR, Jeyarasasingam G, Chalupa LM (1995) Development and regulation of dendritic stratification in retinal ganglion cells by glutamate-mediated afferent activity. J Neurosci 15:7037-7045.

Bonhoeffer T, Grinvald A (1996) Optical imaging based on intrinsic signals: the methodology. In: Brain mapping, The methods (Toga A, Mazziotta JC, eds), pp 55-97. San Diego: Academic.

Buisseret P, Imbert M (1976) Visual cortical cells: their developmental properties in normal and dark reared kittens. J Physiol (Lond) 255:511-525.

Chapman B, Bonhoeffer T (1998) Overrepresentation of horizontal and vertical orientation preferences in developing ferret area 17. Proc Natl Acad Sci USA 95:2609-2614.

Chapman B, Stryker MP (1993) Development of orientation selectivity in ferret visual cortex and effects of deprivation. $\mathrm{J}$ Neurosci 13:5251-5262.

Chapman B, Zahs KR, Stryker MP (1991) Relationship of cortical cell orientation selectivity to alignment of receptive fields of the geniculocortical afferents that arborize within a single orientation column in ferret visual cortex. J Neurosci 11:1347-1358.

Chapman B, Stryker MP, Bonhoeffer T (1996) Development of orientation preference maps in ferret primary visual cortex. J Neurosci 16:6443-6453.

Crair MC, Gillespie DC, Stryker MP (1998) The role of visual experience in the development of columns in cat visual cortex. Science 279:566-570.

Cynader M, Chernenko G (1976) Abolition of directional selectivity in the visual cortex of the cat. Science 193:504-505.

Erwin E, Miller KD (1998) Correlation-based development of ocularly matched orientation and ocular dominance maps: determination of required input activities. J Neurosci 18:9870-9895.

Ferster D (1988) Spatially opponent excitation and inhibition in simple cells of the cat visual cortex. J Neurosci 8:1172-1180.

Fregnac Y, Imbert M (1978) Early development of visual cortical cells in normal and dark-reared kittens: the relationship between orientation selectivity and ocular dominance. J Physiol (Lond) 278:27-44.

Fregnac Y, Trotter Y, Bienenstock E, Buisseret P, Gary-Bobo E, Imbert M (1981) Effect of neonatal unilateral enucleation on the development of orientation selectivity in the primary visual cortex of normally and dark-reared kittens. Exp Brain Res 42:453-466.

Gödecke I, Kim D-S, Bonhoeffer T (1997) Development of orientation preference maps in area 18 of kitten visual cortex. Eur J Neurosci 9:1754-1762.

Grinvald A, Lieke EE, Frostig RD, Gilbert CD, Wiesel TN (1986) Functional architecture of cortex revealed by optical imaging of intrinsic signals. Nature 324:361-364.

Hirsch JA, Alonso JM, Reid RC, Martinez LM (1998) Synaptic integration in striate cortical simple cells. J Neurosci 18:9517-9528.

Horton JC, Sherk H (1984) Receptive field properties in the cat's lateral geniculate nucleus in the absence of $\mathrm{ON}$-center retinal input. J Neurosci 4:374-380.

Hubel DH, Wiesel TN (1962) Receptive fields, binocular interaction and functional architecture in the cat's visual cortex. J Physiol (Lond) 160:106-154.

Hubel DH, Wiesel TN (1965) Binocular interaction in striate cortex of kittens reared with artificial squint. J Neurophysiol 28:1041-1059.

Hubel DH, Wiesel TN (1970) The period of susceptibility to the physiological effects of unilateral eye closure in kittens. J Physiol (Lond) 206:419-436.

Hubel DH, Wiesel TN, LeVay S (1977) Plasticity of ocular dominance columns in monkey striate cortex. Philos Trans R Soc Lond B Biol Sci 278:377-409.

Humphrey AL, Saul AB (1998) Strobe rearing reduces direction selectivity in area 17 by altering spatiotemporal receptive-field structure. J Neurophysiol 80:2991-3004.
Issa NP, Trachtenberg JT, Chapman B, Zahs KR Stryker MP (1999) The critical period for ocular dominance plasticity in ferret visual cortex. J Neurosci 19:6965-6978.

Knapp AG, Schiller PH (1984) The contribution of on-bipolar cells to the electroretinogram of rabbits and monkeys. A study using 2-amino4-phosphonobutyrate (APB). Vision Res 24:1841-1846.

LeVay S, Wiesel TN, Hubel DH (1980) The development of ocular dominance columns in normal and visually deprived monkeys. J Comp Neurol 179:223-244.

Löwel S, Schmidt KE, Kim DS, Wolf F, Hoffsümmer F, Singer W, Bonhoeffer T (1998) The layout of orientation and ocular dominance domains in area 17 of strabismic cats. Eur J Neurosci 10:2629-2643.

Miller KD (1992) Development of orientation columns via competition between ON- and OFF-center inputs. NeuroReport 3:73-76.

Miller KD (1994) A model for the development of simple cell receptive fields and the ordered arrangement of orientation columns through activity-dependent competition between ON- and OFF-center inputs. J Neurosci 14:409-441.

Pasternak T, Schumer RA, Gizzi MS, Movshon, JA (1985) Abolition of visual cortical direction selectivity affects visual behavior in cats. Exp Brain Res 61:214-217.

Penn AA, Riquelme PA, Feller MB, Shatz CJ (1998) Competition in retinogeniculate patterning driven by spontaneous activity. Science 279:2108-2112.

Reid RC, Alonso JM (1995) Specificity of monosynaptic connections from thalamus to visual cortex. Nature 378:281-284.

Ruthazer ES, Baker GE, Stryker MP (1999) Development and organization of ocular dominance bands in primary visual cortex of the sable ferret. J Comp Neurol 407:151-165.

Shatz CJ, Stryker MP (1978) Ocular dominance in layer IV of the cat's visual cortex and the effects of monocular deprivation. J Physiol (Lond) 281:267-283.

Shatz CJ, Stryker MP (1988) Prenatal tetrodotoxin infusion blocks segregation of retinogeniculate afferents. Science 242:87-89.

Shatz CJ, Lindström S, Wiesel TN (1977) The distribution of afferents representing the right and left eyes in the cat's visual cortex. Brain Res 131:103-116.

Slaughter MM, Miller RF (1981) 2-Amino-4-phosphonobutyric acid: a new pharmacological tool for retinal research. Science 211:182-184.

Sretavan DW, Shatz CJ, Stryker MP (1988) Modification of retinal ganglion cell axon morphology by prenatal infusion of tetrodotoxin. Nature 336:468-471.

Stryker MP, Harris WA (1986) Binocular impulse blockade prevents formation of ocular dominance columns in the cat's visual cortex. J Neurosci 6:2117-2133.

Stryker MP, Strickland SL (1984) Physiological segregation of ocular dominance columns depends on the pattern of afferent electrical activity. Invest Opthalmol Vis Sci [Suppl] 25:278.

Tanaka K (1983) Cross-correlation analysis of geniculostriate neuronal relationships in cats. J Neurophysiol 49:1303-1318.

Tanaka K (1992) A mathematical model for the self-organization of orientation columns in visual cortex. NeuroReport 3:69-72.

Weliky M, Katz LC (1997) Disruption of orientation tuning in visual cortex by artificially correlated neuronal activity. Nature 386:680-685.

Weliky M, Katz LC (1999) Correlational structure of spontaneous neuronal activity in the developing lateral geniculate nucleus in vivo. Science 285:599-604.

Wiesel TN, Hubel DH (1963) Single-cell responses in striate cortex of kittens deprived of vision in one eye. J Neurophysiol 26:1003-1017.

Wiesel TN, Hubel DH (1974) Ordered arrangement of orientation columns in monkeys lacking visual experience. J Comp Neurol 158:307-318.

Wong RO (1999) Retinal waves and visual system development. Annu Rev Neurosci 22:29-47.

Wong WT, Myhr KL, Miller ED, Wong ROL (2000) Developmental changes in the neurotransmitter regulation of correlated spontaneous retinal activity. J Neurosci, in press.

Zahs KR, Stryker MP (1988) Segregation of on and off afferents to ferret visual cortex. J Neurophysiol 59:1410-1429. 